\title{
Chemical interaction between polymer and cement in polymer-cement concrete
}

\author{
R. WANG ${ }^{1}$, J. $^{2}{ }^{1}$, T. ZHANG ${ }^{1}$, and L. CZARNECKI ${ }^{2 *}$ \\ ${ }^{1}$ Key Laboratory of Advanced Civil Engineering Materials of Ministry of Education, School of Materials Science and Engineering, \\ Tongji University, 4800 Cao'an St., Shanghai 201804, China \\ ${ }^{2}$ Building Research Institute (ITB), 1 Filtrowa St., 00-611 Warsaw, Poland
}

\begin{abstract}
Polymers are widely used in cement mortar and concrete modification due to their significant role in improving the overall performance of cement-based materials. Their physical interaction is well-accepted, while less attention is given to chemical interaction between the polymers and cement. Through a review of prior arts, chemical interactions are discussed and summarized in this paper. Various chemical interactions may take place between cement and different types of polymers. Understanding these chemical interactions will play an important role in clarifying the relationship between microstructure and macrostructure of polymer-modified cementitious materials. Authors expressed and proved the conviction that the organic-inorganic (Polymer-Portland cement) composite with some components chemically bonded, in parallel to the physical interaction, will be the next stage in concrete technology progress.
\end{abstract}

Key words: Chemical interaction, polymer, Portland cement, concrete-polymer composites, polymer cement concrete.

\section{Introduction}

Concrete is the most popular construction material in the world. Polymer cement concretes are the result of the permanent search for a better concrete. Being used for centuries, concrete was often modified using natural polymers [1]. Within the last almost-one-hundred years, synthetic polymers [2] have been employed in the modification of concrete (Polymer-cement concretes - PCCs, polymer-impregnated concretes PICs), and even to the manufacturing of cement-less concretes (resin concretes). The concept of using concrete-polymer composites (C-PCs) was changing with time as the scientific bases of microstructure formation were being recognized, and thus, also formation of the properties of those materials got known better. In 1950-70s, the introduction of polymer into concrete was an evidence of "progress" and "modernity". This was accompanied by the fascination with the merger of a very old, traditional material - concrete (inorganic!), with the most modern one - a polymer (organic!) [3]. Also, there was an opinion, not justified and not verified in that time, that any addition of any polymer should improve the properties of concrete. The aims of development of polymer-cement concrete have been reoriented as a result of a better understanding of the mechanisms of concrete modification by polymers. However, there are some economical restrictions. The cost of polymer, depending on its type, is 10-100 times higher than the cost of Portland cement considering the mass units, and 5-25 times higher considering volume units. This is a significant limitation, in spite of the fact that the share of polymers in the construction composite is usually above $5 \%$, but not

*e-mail: 1.czarnecki@itb.pl higher than $10 \%$ of cement mass. Because of the synergic action of polymers in concrete, their influence on the properties of the product is much higher than one could deduct from their mass/volume share [4]. We can observe several milestones on the road to building the PCC microstructure formation model [5]. Particularly Bares's model, Ohama model, and Beeldens-Ohama-Van Gemert integrated model should be stressed among others (Table 1).

Years 2005-2009 have brought the breakthrough achievement of Van Gemert and Knapen [16, 17]. If we use a water-soluble polymer (WSP) instead of a liquid polymer, due to the thermodynamic conditions, the WSP will be placed in the nano-area. As a result of changing the polymer position from micro-area into nano-area, the polymer will not be bridging between the crack-edges of concrete, but between the hexagonal plates of Portlandite [Fig. 1]. In such situation, even an addition of polymer in the amount of $1 \%$ of cement mass will improve the tensile strength $50 \%$ more than with $10 \%$ polymer content in an ordinary situation. a)

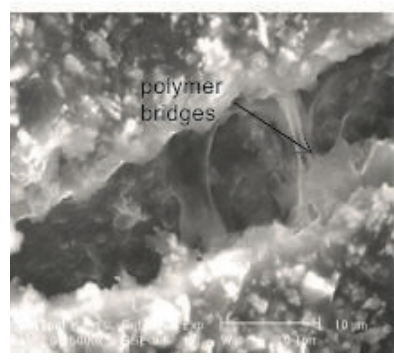

b)

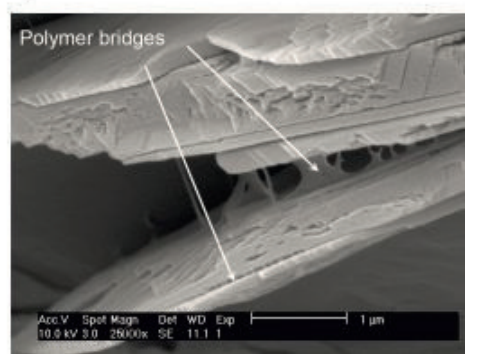

Fig. 1. (a) Polymer bridging between crack-edges of concrete [14] on micro-level, and (b) between Portlandite crystal plates [5] on nano-level 
Table 1

PCC microstructure formation models; milestones

\begin{tabular}{|c|c|c|c|c|c|}
\hline $\begin{array}{l}\text { Mile- } \\
\text { stone } \\
\text { no }\end{array}$ & Year & Authors & Description & Remarks & Ref. \\
\hline I & $\begin{array}{l}1985 \\
-1987\end{array}$ & $\begin{array}{l}\text { R. Bares, } \\
\text { D. Van Gemert, } \\
\text { L. Czarnecki }\end{array}$ & Bares's model - structure engineering approach & $\begin{array}{l}\text { Quite useful for engineering applica- } \\
\text { tion }\end{array}$ & {$[6,7]$} \\
\hline II & 1987 & Y. Ohama & $\begin{array}{l}\text { Ohama's model; three-step model; polymer phase } \\
\text { interpenetrates through the cement hydrate phase }\end{array}$ & $\begin{array}{l}\text { The model makes base for PCC devel- } \\
\text { opment and application }\end{array}$ & [8] \\
\hline III & 1995 & J. Bijen, Z. Su & $\begin{array}{l}\text { Modification of the three-step model; polymer is } \\
\text { highly non-uniformly distributed in concrete }\end{array}$ & Imbibition effect & [9] \\
\hline IV & 1998 & $\begin{array}{l}\text { M. Puterman, } \\
\text { W. Malomy }\end{array}$ & $\begin{array}{l}\text { Modification of the three-step model; if the MFFT* } \\
\text { is above the curing temperature, the polymer layer } \\
\text { will not form a continuous film }\end{array}$ & $\begin{array}{l}\text { Lots of questions have been done } \\
\text { which will orient further researches }\end{array}$ & {$[10]$} \\
\hline $\mathrm{V}$ & 2001 & $\begin{array}{l}\text { H. Schorn, } \\
\text { M. Schiekel }\end{array}$ & $\begin{array}{l}\text { Modification of the three-step model's uniform poly- } \\
\text { mer-concrete distribution; if the MFFT is lower than } \\
\text { the working temperature a quasi-homogenous poly- } \\
\text { mer film is formed }\end{array}$ & & {$[11]$} \\
\hline VI & 2005 & $\begin{array}{l}\text { A. Beeldens, } \\
\text { D. Van Gemert, } \\
\text { Y. Ohama }\end{array}$ & $\begin{array}{l}\text { Beeldens-Ohama-Van Gemert model - Integrated } \\
\text { model }\end{array}$ & $\begin{array}{l}\text { The positioning of the mechanism on } \\
\text { a time scale; the interaction between } \\
\text { the different components }\end{array}$ & {$[12]$} \\
\hline VII & 2007 & $\begin{array}{l}\text { L. Czarnecki, } \\
\text { H. Schorn }\end{array}$ & Nano monitoring of a polymer in concrete & $\begin{array}{l}\text { The advantages of ESEM** method } \\
\text { have been shown }\end{array}$ & {$[13]$} \\
\hline VIII & 2007 & $\begin{array}{l}\text { A. Dim- } \\
\text { mig-Osburg }\end{array}$ & $\begin{array}{l}\text { Modification of the integrated model: polymer floc- } \\
\text { culation }\end{array}$ & $\begin{array}{l}\text { The drying period of concrete will } \\
\text { cause the condensation of the polymer } \\
\text { film and the enhancement of adhesion }\end{array}$ & {$[14]$} \\
\hline IX & 2011 & $\begin{array}{l}\text { Y. Tian, Z. Li, } \\
\text { H. Ma, N. Jin }\end{array}$ & $\begin{array}{l}\text { Modification of the integrated model: localization of } \\
\text { polymer modification }\end{array}$ & Imbibition effect & {$[15]$} \\
\hline$X$ & $\begin{array}{l}2005 \\
-2009\end{array}$ & $\begin{array}{l}\text { E. Knapen, } \\
\text { A. Beeldens, } \\
\text { D. Van Gemert }\end{array}$ & $\begin{array}{l}\text { Water soluble polymer as the most effective modi- } \\
\text { fier: polymer nano-bridging of the Portlandite crystal } \\
\text { plates infer macro-bridging of concrete crack-edges }\end{array}$ & $\begin{array}{l}\text { A breakthrough achievement, most } \\
\text { likely opening a new era in modifica- } \\
\text { tion of polymer-cement concrete }\end{array}$ & $\begin{array}{l}{[16]} \\
{[17]}\end{array}$ \\
\hline
\end{tabular}

*MFFT - minimum film forming temperature

**ESEM - environmental scanning electron miscroscopy

Until now, it is a top achievement in polymer-cement concrete technology and is very promising for future. And there always stood the fundamental question: how does a polymer improve the concrete?

It should be stressed that the presented above polymer-cement concrete technology development and adequate microstructure modeling is involved only and solely with the physical mechanisms and physical interaction by which the synergy phenomenon is realized. The physical interactions occur in the system, and in most cases, a polymeric film is formed inside the composite, which is responsible for the improvement of the hardened-state properties of mortars and concretes. Comparing with physical interaction, the chemical interaction is out of focus in many cases. But the important role of chemical interaction has been only very rarely denied $[18,19]$. Every innovation starts with the idea. The authors are convinced that in PCC technology:

- polymer-cement-like mixture governed by the rule of mixture, followed by a polymer-cement-composite, relevant to synergy based on physical interaction between components,

- the next stage will be the organo-inorganic composite, in which some components are chemically bonded, parallel to the physical interactions. It should open new possibilities and expectations for further progress.

A clear picture of the chemical interaction that happens between the cement and polymer will be a good supplement to theories on physical interactions. Through reviewing the existing research on chemical interactions between different 
polymers and cement in PCC, this paper summarizes the findings in this area so far. Looking at the problem from another perspective will help to understand the application performance of these polymers in cement-based material modification.

Popular polymers that are used in cement mortar or concrete modification [20] include latex polymer in the form of emulsion or redispersible powder, such as ethylene-vinyl acetate copolymer (EVA), acrylics, vinyl acetate and versatate copolymer (Va-VeoVA), water soluble polymer such as cellulose ether, starch ether, polyacrylamide, polyvinyl alcohol (PVA) and so on. Each type of polymer has its unique characteristics in cement modification [21-28]. Some of them are slightly different, while other are quite opposite. Chemical interaction could result in the formation of complex structures, changes in the hydrated cement phases morphology, composition and quantities [29-31].

Various works have been conducted to understand the chemical interactions between polymers and cement. Typically, two approaches are used in the research process: one is to evaluate the chemical interactions in simulated pore solution, and the other is to do it in cement or a cement-containing paste. The existing research on chemical interaction between polymer and cement specifically refers to EVA and acrylic polymers in this paper.

\section{Negative experience from the past: PVAc hydrolisation}

Polymers should cause a modification of the concrete microstructure, leading to positive changes in its properties (synergic effects). The requirement of necessity is an intrinsic compatibility among polymer and other concrete components. Polymers could affect the Portland cement hydration in various ways. There is a very instructive example from the past. In the 1960s and 1970s, polyvinyl acetate (PVAc) has been very commonly used as a concrete modifier [32]. After a long period of trials and tribulations, PVAc was practically excluded from the polymers-in-concrete list. The reason was its chemical interaction with calcium hydroxide, the product of Portland cement hydration. In alkaline environment of the cement paste, the hydrolysis of PVAc takes place (Fig. 2). The next stage is the formation of calcium acetate crystal (Fig. 3). The calcium acetate crystal dimension is very unstable, due to its hygroscopic properties. Eventually, the end-properties of the concrete could deteriorate.

However, the polymers' hydrolyzation ability does not always provide negative result. In the case of polyacrylate, the bidentate calcium complex is the end product, and it causes

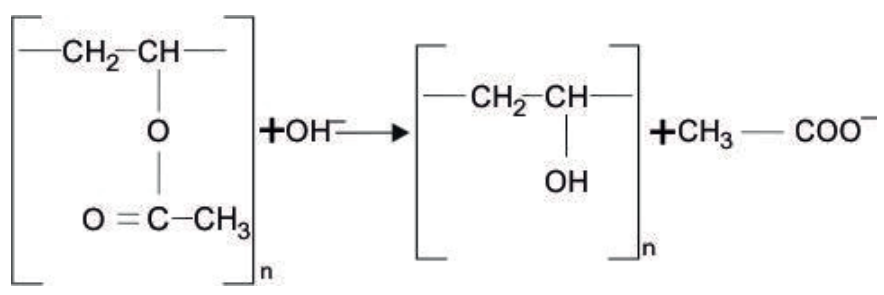

Fig. 2. Hydrolysis of PVAc in alkaline environment

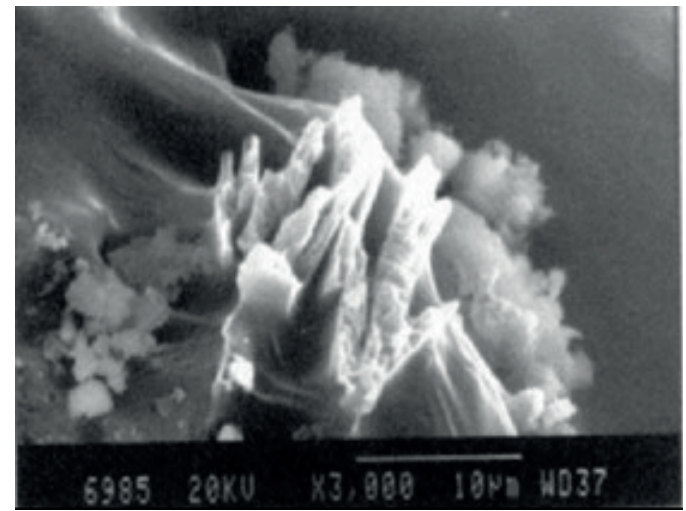

Fig. 3. Calcium acetate crystals as the product of hydrolysis of PVAc in cement paste [33]

better crosslinking of the polymer network and diminishes the profitably of the content of free calcium hydroxide (see chapter 4.3).

\section{Ethylene-vinyl acetate copolymer}

Ethylene-vinyl acetate (EVA) copolymer is one of the most popular polymers that are used to modify cement mortar and concrete, due to its balanced performance and cost. Research works have been conducted to observe the interaction, at both early and late stages of cement hydration, through various analysis methods.

It is generally believed that the vinyl acetate group contained in the EVA copolymer suffers hydrolysis when dispersed in an alkaline medium $[33,34]$, and that process is called saponification. When EVA is dispersed in a $\mathrm{Ca}(\mathrm{OH})_{2}$-saturated solution, as in the case of pore solution of cement pastes, the acetate anion $\mathrm{CH}_{3} \mathrm{COO}^{-}$released in the alkaline hydrolysis of EVA combines with $\mathrm{Ca}^{2+}$ released in the dissolution of cement grains, as shown in (1), and the product of this interaction is calcium acetate $\mathrm{Ca}\left(\mathrm{CH}_{3} \mathrm{COO}\right)_{2}$.

$$
\mathrm{Ca}(\mathrm{OH})_{2}+2 \mathrm{CH}_{3} \mathrm{COO}^{-} \rightarrow \mathrm{Ca}\left(\mathrm{CH}_{3} \mathrm{COO}\right)_{2}+2 \mathrm{OH}^{-}
$$

Silva et al. [30] studied the interaction between EVA and hydrating Portland cement at a constant water/cement ratio with samples cured for 28 days, trying to find evidence of chemical interaction between them. The results showed that the acetate groups of EVA copolymer undergo alkaline hydrolysis and interact with $\mathrm{Ca}^{2+}$ of the pastes to form calcium acetate. EVA causes some modifications in the FTIR spectra profile (Fig. 4) with a band at $1558-1568 \mathrm{~cm}^{-1}$. This indicates the presence of carboxylate anion in the EVA-modified pastes, confirming that alkaline hydrolysis of acetate groups has occurred. The band at $1740-1742 \mathrm{~cm}^{-1}$ indicates that the hydrolysis is not complete, i.e. that some acetate groups rest bonded to the EVA main chain. EVA probably retards the precipitation of hydrated phases due to the consumption of $\mathrm{Ca}^{2+}$ from the aqueous phase and absorption on hydrated and anhydrous cement phases. The 


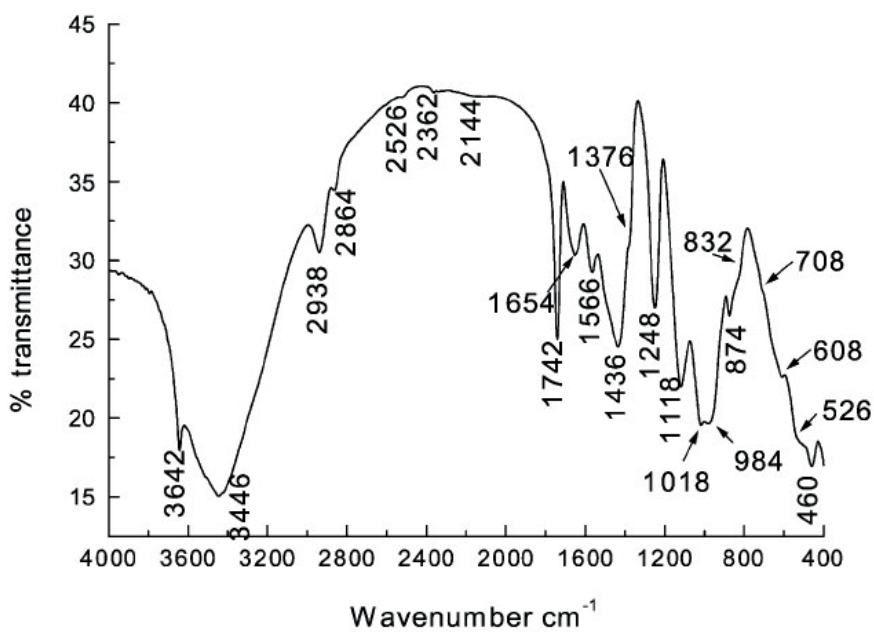

Fig. 4. Fourier-transform infrared spectrum of $20 \%$ EVA-modified cement paste, 28 days old [30]

$\mathrm{Ca}(\mathrm{OH})_{2}$ content is decreased, the ettringite crystals appear to be well-formed, and many Hadley's grains are observed. A calcium-rich, porous, hexagonal structure phase was detected, probably due to an acetic-acid-attack on $\mathrm{Ca}(\mathrm{OH})_{2}$ crystals.

Betioli et al. [35] study chemical interaction between EVA and Portland cement hydration at its early age, during the first hours through TG/DTG. The polymer/cement ratio is between $5-10 \%$, and water/cement ratio is constant at 0.38 . The results confirm that the interaction as shown in (1) occurred in the first 15 minutes of hydration. This interaction was verified in the first 15 minutes by the absence of the dehydration peak in TG analyses until 5 and 6 hours in EVA-modified pastes, with 5\% and $10 \%$ EVA, respectively. The new peak, observed at $380^{\circ} \mathrm{C}$, referred to the first calcium acetate decomposition and increase in $\mathrm{CO}_{2}$ release, due to calcium carbonate forming during the decomposition of calcium acetate. At the same time, it was pointed out that this chemical interaction probably decreased the EVA flexibility, thus promoting the increase of elasticity modulus of cement-based materials.

Some evidence of chemical interaction between EVA and $\mathrm{C}_{3} \mathrm{~A}$ in the first hours of hydration was observed by soft X-ray transmission microscopy [36]. The hydration of pure $\mathrm{C}_{3} \mathrm{~A}$ $\left(\mathrm{Ca}_{3} \mathrm{Al}_{2} \mathrm{O}_{6}\right)$ in calcium hydroxide-gypsum-saturated solution was analyzed. The images show the presence of at least two different types of ettringite crystals during the first 4 hours of hydration. They differ in morphology and growth rate. When EVA is present, there is a significant change in hydration kinetics and morphology of the hydration products. EVA particles inhibited, or even prevented the formation of ettringite crystals during the early stage of hydration. A cloud of small, bright particles is observed concentrated around the hydrating $\mathrm{C}_{3} \mathrm{~A}$ grains. The particles are believed to be a product of a reaction between EVA and inorganic species in the solution.

Single pulse excitation (SPE) ${ }^{43} \mathrm{Ca}$ and ${ }^{13} \mathrm{C}$ NMR spectroscopies were used to monitor the hydrolysis of EVA in white cement with very low iron content over a three-month period by MacDonald et al. [37]. Control samples of white cement with different fluoropolymers as admixtures (Teflon and perfluoroalkoxy, denoted PFA) were used, as such hydrophobic polymers are likely to interact only very weakly with the cement. The formation of the hydrolysis product, calcium acetate, was monitored semi-quantitatively by ${ }^{13} \mathrm{C}$ NMR spectroscopy, through the formation of a well-resolved peak at $181 \mathrm{ppm} .{ }^{43} \mathrm{Ca} \mathrm{NMR}$ shows both that EVA induces modest changes in the hydrated cement structure, and that hydrated commercial cement is significantly more complex than the models that have been used for its structure in past work. Comparing with the control samples, the spectra of the hydrated cement samples with EVA additives show additional weak signals above $67 \mathrm{ppm}$, up to about $110 \mathrm{ppm}$. These new signals were assigned to low-coordinated calcium sites with small average bond lengths. Evidence of calcium acetate formation was observed in the SPE and $\mathrm{CP}^{13} \mathrm{C}$ NMR spectra, as can be seen in Fig. 5. The spectrum of EVA/white cement at 56 days of hydration shows a new peak with the maximum around $181 \mathrm{ppm}$, not seen in pure EVA. The SPE ${ }^{13} \mathrm{C}$ NMR spectrum of hydrated cement without the EVA additive shows no significant ${ }^{13} \mathrm{C}$ signal. This proves that the new peak at $181 \mathrm{ppm}$ is due to the EVA/ cement interaction. Spectral broadening of the $\mathrm{CHO}$ and $\mathrm{CH}_{2}$ resonances between pure latex and the modified hydrated cement may reflect the effect of EVA hydrolysis, or the higher mobility of the polymer in its native state, compared to the more restricted environment in the hardened cement. The SPE ${ }^{13} \mathrm{C}$ NMR spectra of EVA/white cement paste with hydration times ranging from 1 to 84 days, showed an appearance and increase of the peak at $181 \mathrm{ppm}$ in hydration times longer than 1 day. EVA hydrolysis continues, and produces increasing amounts of $\mathrm{Ca}\left(\mathrm{CH}_{3} \mathrm{COO}\right)_{2}$, until about 15 days of hydration time.

\section{Acrylic polymers}

4.1. Polyacrylate. The interaction between acrylic polymers and cement was also studied widely. In the literature by Ma et al. [38-40], in order to simulate the potential reaction between latexes and the pore solution, a saturated $\mathrm{Ca}(\mathrm{OH})_{2}$ solution was used. Calcium chloride was used for confirming the effect of
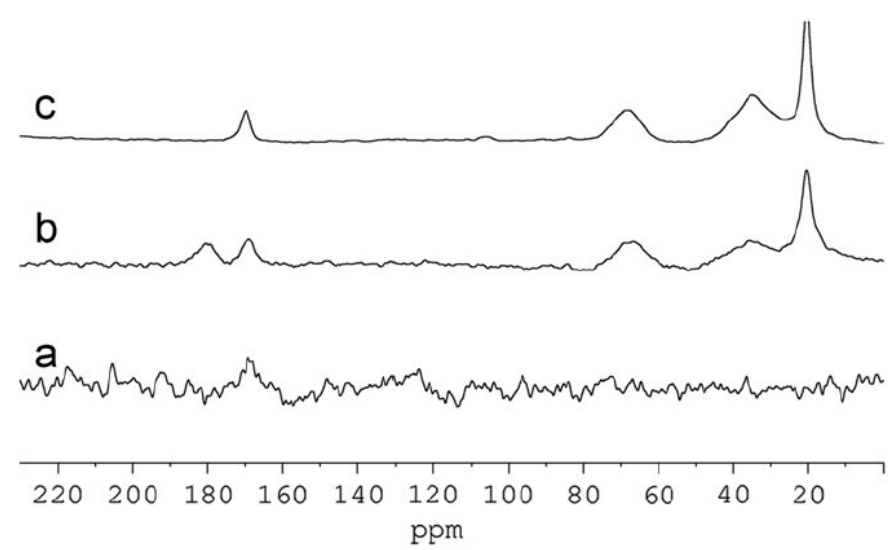

Fig. 5. SPE ${ }^{13} \mathrm{C}$ MAS NMR spectra of (a) white cement without additives after 56 days of hydration, (b) hydrated EVA/white cement after 56 days of hydration, (c) EVA [37] 
calcium ions, sodium hydroxide for eliminating the effect of an alkaline environment, and sodium chloride for eliminating the confusion with chloride ions. Latex and water were first injected into a test tube and shaken to uniformity, and then the solid powders were added. The tubes were shaken and placed under observation. In the mixtures of polyacrylate (PA) latex and $\mathrm{Ca}(\mathrm{OH})_{2}$ or $\mathrm{CaCl}_{2}$, demulsification and flocculation happened within 30 minutes after mixing, and gradually, these systems were reaching their stable states. In the mixtures of PA and $\mathrm{NaOH}$ or $\mathrm{NaCl}$, no demulsification or flocculation happened, as shown in Fig. 6. The authors attribute the demulsification to the reaction between calcium ions and sodium dodecyl sulfonate used in preparing the PA emulsion, and believe that calcium ions may partake in the flocculation and act as a cross-linking agent. Similar tests were conducted on the PA-cement mixture, with (a)

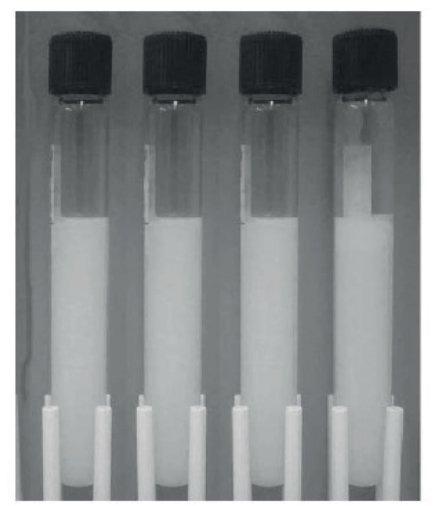

(b)

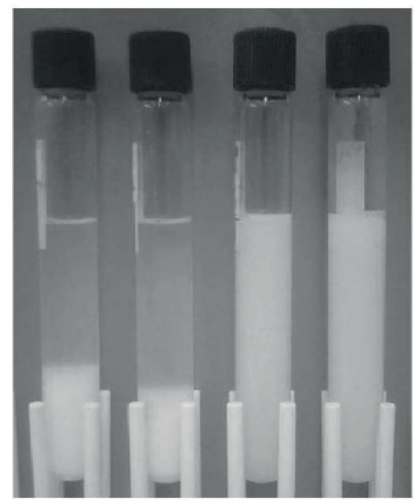

Fig. 6. Flocculation in mixtures of PA latex and inorganic salts: (a) immediately after mixing, (b) stable state (from left to right, the salts in mixture are $\mathrm{Ca}(\mathrm{OH})_{2}, \mathrm{CaCl}_{2}, \mathrm{NaOH}$, and $\mathrm{NaCl}$, respectively) [38]

similar results achieved. Four layers were identified in the stable mixture, including: supernatant liquid, flocculation, yogurt-like layer (or coagulation) and cement-PA compound, counting from top to bottom. This is perceived to be a result of solubility and density differences of the reaction products. Through using various analysis methods, including EDX, SEM, TGA, XRD, and FTIR, the study showed that PA molecules chemically react with cement hydrates to form a compound. Fig. 7 shows the reaction between $\mathrm{Ca}^{2+}$ and a PA polymer chain $[39,40]$. An improved 4 -step model was proposed to describe the forming process of the microstructure of PA polymer-modified cement mortar. Taking the chemical reactions between cement hydrates and polymer latex into consideration, the corresponding influence of polymer latex on cement mortars was represented in the model.

It was reported by Long et al. [41] that a polyacrylate can react with cement hydrates and forms an interpenetrated network with big molecules composed by ion bond, therefore densifying the cement hydrates, resulting in less water penetration. This finding was also confirmed by Gao et al. [42].

4.2. Styrene/acrylic ester copolymer. FTIR analysis indicates that $\mathrm{Ca}^{2+}$-carboxyl complexes form during the hydration of cement paste containing styrene-acrylic ester (SAE) powder [43].

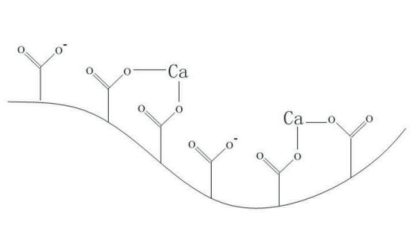

PA polymer chain

(a) Self-link of polymer chain

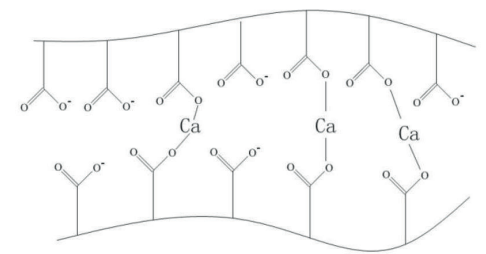

PA polymer chain

(b) Cross-link of PA polymer chains

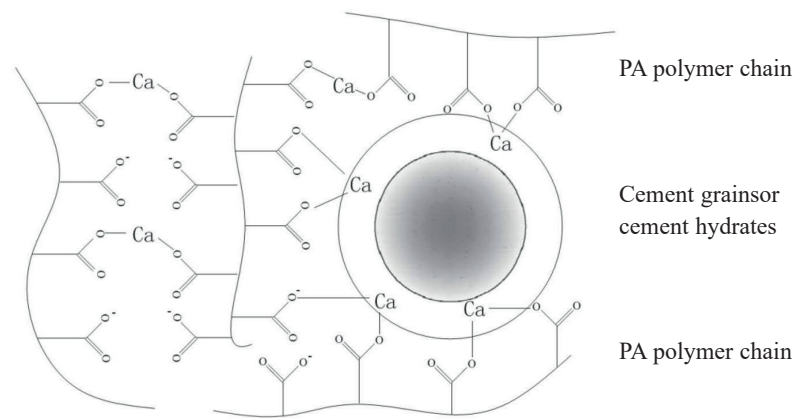

(c) Cross-link between PA polymer chain and cement hydrates

Fig. 7. Reaction between $\mathrm{Ca}^{2+}$ and PA polymer chain [39]

The absorption peak, which occurs between $1729-1735 \mathrm{~cm}^{-1}$ (Fig. 8), corresponds to $\mathrm{C}=\mathrm{O}$ in the SAE powder-modified cement pastes, while the same group appears in pure SAE powder at $1728 \mathrm{~cm}^{-1}$. The peak drifts to a higher wave number (from $1728 \mathrm{~cm}^{-1}$ to $1735 \mathrm{~cm}^{-1}$ ) as the SAE addition is increased. The possible reason for the absorption peak drift is that one pair of electrons belonging to $-\mathrm{O}-$ in $\mathrm{COO}^{-}$moves to the $\mathrm{Ca}^{2+}$ in the system, reducing the electronic cloud density around - $\mathrm{O}_{-}$ and around the $\mathrm{C}=\mathrm{O}$ connected to it. The spectrum change shows that $\mathrm{O} \rightarrow \mathrm{Ca}^{2+}$ coordination bonds, and thus $\mathrm{Ca}^{2+}$-carboxyl complexes exist. Meanwhile, according to the acid-base protons theory, $\mathrm{Ca}^{2+}$ is a strong acid and $\mathrm{COO}^{-}$is a strong base, therefore stable $\mathrm{Ca}^{2+}$-carboxyl complexes will form in the SAE powder-modified cement paste.

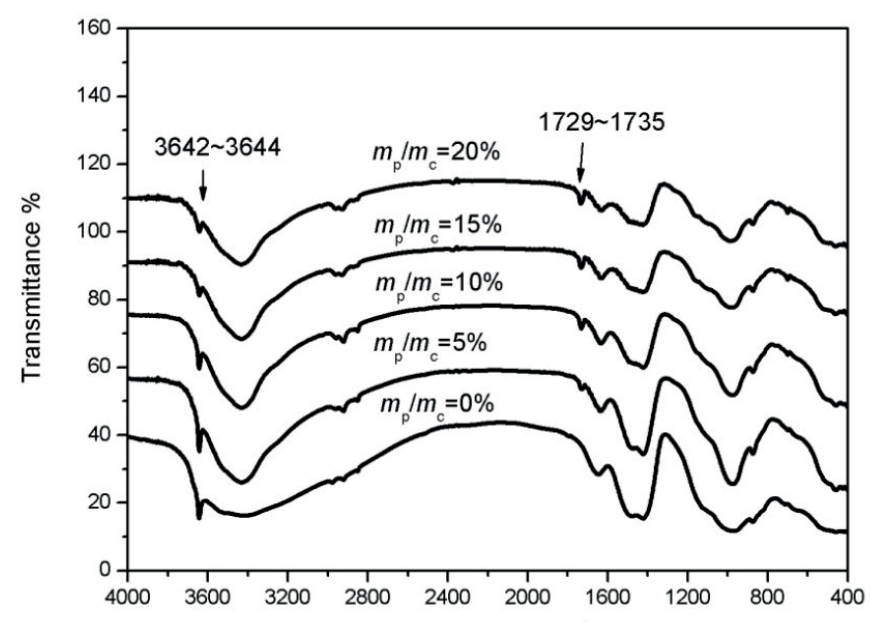

Fig. 8. FTIR spectra of cement pastes, with and without SAE powder, cured for 28 days $\left(m_{p} / m_{c}\right.$ is polymer/cement ratio) [43] 
Chandra et al. [44] conducted research on the interaction between calcium hydroxide and SAE, and found that the latex containing soft microparticles of $0.1 \mu \mathrm{m}$ diameter affect the crystallization of calcium hydroxide. These small particles precipitate on the surface of crystals, and form a thin film. The ion bond, formed between a calcium ion and a polycarboxylate, improves the binding strength between the small particles. The reaction mechanism is illustrated in Fig. 9.

(a)

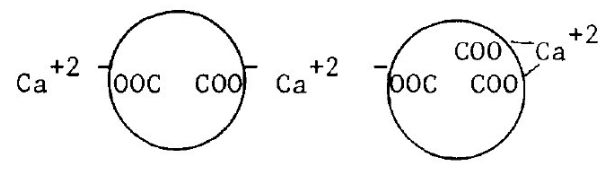

(b)

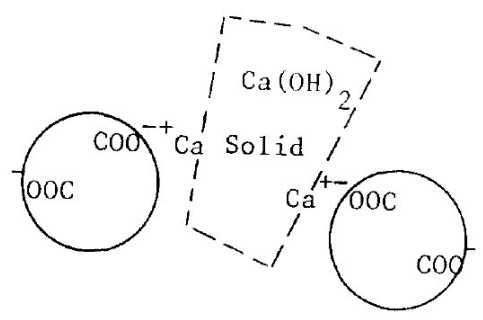

Fig. 9. Schematic illustration of cross-linking of polymer particles by (a) divalent $\mathrm{Ca}$-ions and (b) $\mathrm{Ca}(\mathrm{OH})_{2}$ solid particles [44]

The interaction between $\mathrm{Ca}^{2+}$ and several ionic latex dispersions synthesized with styrene, n-butyl acrylate, methacrylic acid, and either anionic or cationic surfactants have also been claimed by Plank and Gretz [45], who measured the streaming potential of the colloidal particles as a function of the $\mathrm{Ca}^{2+}$ concentration.

4.3. Poly(sodium acrylate). Properties and interactions of ordinary Portland cement with absorbent polymer sodium acrylate $((\mathrm{CH}) \mathrm{nCOONa})$ in the hardened cement pastes were studied by Rha et al. [46]. The chemical difference between cement pastes with and without absorbent polymer was found by the inductively coupled, plasma-atomic emission spectroscopy (ICP) and IR spectroscopy. With the use of ICP, the values of $\mathrm{Ca}^{2+}$ concentration in the solutions leached from the cement paste and the absorbent polymer gel were found to be 390 and 50 ppm respectively. If there is no interaction between the cement and the absorbent polymer, the theoretical value of $\mathrm{Ca}^{2+}$ concentration in a solution leached from cement-absorbent polymer paste should show $220 \mathrm{ppm}$ as the average value, but actually, it shows 90 ppm. This means that the interaction between the cement and absorbent polymer is stronger than the coercive filtering pressure. For the IR spectra of absorbent polymer in Fig. 10, bands at 1416 and $1560 \mathrm{~cm}^{-1}$ were assigned to $\mathrm{C}-\mathrm{O}$ single bond and $\mathrm{C}=\mathrm{O}$ double bond respectively, forming a unidentate complex. As the curing time increased, the absorption bands near $1416 \mathrm{~cm}^{-1}$ shifted to a longer wave number, and the absorption

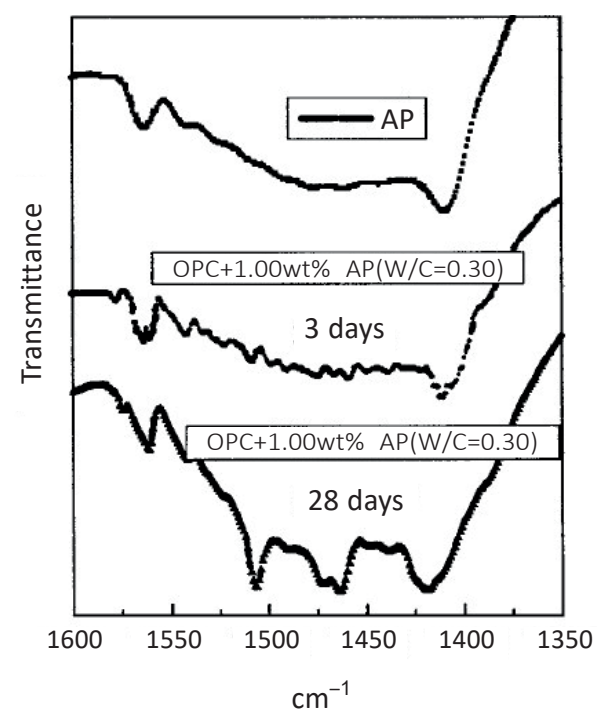

Fig. 10. IR spectra of ordinary Portland-cement paste with absorbent polymer as a function of time [46]

bands near $1560 \mathrm{~cm}^{-1}$ shifted to a shorter wave number, and finally, a bidentate complex was formed. The absorbent polymer released sodium ions to the pore solution under the basic condition of $\mathrm{pH} 12.5-13.5$, and became a polyacrylic acid. Then, some of these polyacrylic acid particles were crosslinked with others by $\mathrm{Ca}^{2+}$ leached from cement grains. $\mathrm{Ca}^{2+}$ was regarded the central charge, connecting the negative parts in carbon-oxygen polarization of the absorbent polymer's functional groups. The unidentate complex (absorbent polymer), as a starting material, converted to a bidentate (chelate) complex (Fig. 11).

a)<smiles></smiles>

b)

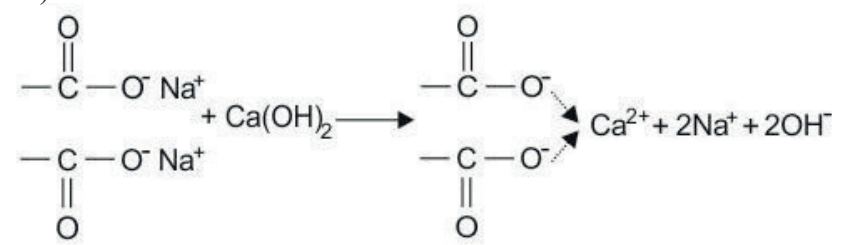

c)<smiles></smiles>

Fig. 11. Schematic structure of calcium chelate polymer complex forming: a) hydrolysis of ester bond in alkali environment b) complex reaction c) bidentate complex forming - calcium polyacrylate 
4.4. Polyacrylamide (PAM). PAM is a type of water-soluble polymer that is used in cement modification as a viscosity-modifying agent. Its chemical interaction with cement was also studied by some researchers. Hu et al. [47] analyzed the characteristics of the hydration system between PAM and monocalcium aluminate. Through hydration heat and XRD analyzing, it was found that the additionally consumed $\mathrm{Ca}^{2+}$ and $\mathrm{Al}^{3+}$ ions (compared with a control sample, which does not have PAM) do not participate in the crystallization of $\mathrm{C}_{3} \mathrm{AH}_{6}$ hydrates, and they were believed to have a chemical reaction with PAM.

Choonkeum et al. [48] have studied the effect of introducing an inorganic cation with a different valence into cement- and PAM-based MDF cementitious materials. Through FTIR, XRD, EDS, etc. analyses, it was confirmed that PAM is easily hydrolyzed in alkali solution into polyacrylic acid, and reacts with metal ions, forming cross-linked metal polyacrylates. In calcium silicate cementitious system, PAM reacts into polyacrylate acid and releases ammonium. Then, the polyacrylic acid reacts with the metal cation released during cement hydration. When new ions are introduced into the cement-PAM system, the multivalent ions $\left(\mathrm{Ca}^{2+}, \mathrm{Al}^{3+}\right)$ can react with the polyacrylic acid and form a stable molecular structure, which has a limited influence on cement hydration. On the other hand, monovalent positive ions $\left(\mathrm{K}^{+}, \mathrm{Na}^{+}\right)$react with polyacrylic acid into unstable salts, which in turn accelerate cement hydration. It also accelerates the reaction speed between the polymer and the metal ions that are released during cement hydration.

\section{Conclusions}

The progress in concrete technology has been done mainly by material modification $[49,50]$. Polymers as modifiers in concrete have been playing a significant function, until now. Authors believe that the further progress will be done by means of an organic-inorganic composite, in which some components are chemically bonded, parallel to the physical interactions. If the two phases: polymer and Portland cement paste, are additionally partially linked together, through strong chemical covalent or iono-covalent bonds, it gives extra cohesion to the whole structure, and enhances the technical properties [51].

The existing research publications have demonstrated a lot of evidence of chemical interaction between polymers and cement in concrete-polymer composites through various analytical methods, including IR spectroscopy, thermal analysis, NMR microscopy etc. Some of the reactions explain the failure mode of this type of materials, such as the hydrolysis of ester group. Others explain the strengthening mechanisms, such as the formation of chelates. In comparison to physical interactions, there are more controversies in chemical interactions. Thus, it would be very helpful in future to collect more specific evidence of chemical interaction and quantify the influence of these chemical interactions on the performance of polymer-modified cementitious materials, in order to deepen the understanding of chemical interactions between polymers and cements. Chemical and physical interactions between cements and polymers are two sides of the same coin. Only when the chemical interactions between polymers and cements are clearly understood can people better explain the micro- and macrostructure relationship in concrete-polymer composites, which in turn serves the purpose of developing higher-performance materials. Today we are just a step before this potential becomes reality. The goal of this paper is to raise awareness of this opportunity.

Acknowledgments. The authors acknowledge the financial support by the National Natural Science Foundation of China (51572196 and 51202162), the Fundamental Research Funds for the Central Universities (0500219229) and Sino-German Center for Research Promotion (GZ 1290).

\section{REFERENCES}

[1] S. Chandra, "Historical background of polymers used in concrete", $8^{\text {th }}$ International Congress on Polymers in Concrete (ICPIC'1995), Ostend, Belgium, 3-11 (1995).

[2] L. Cresson. "Improved manufacture of rubber road-acing, rubber-flooring, rubber-tiling or other rubber-lining", British patent No. 191,474, 1923.

[3] L. Czarnecki, "Concrete-polymer composites C-PC - Reading with understanding", Restoration of buildings and monuments 18 (3-4), 135-142 (2012).

[4] D. Van Gemert, "Synergies between polymers and cement concrete providing opportunities for sustainable construction", $A d$ vanced Materials Research 687, 12-20 (2013).

[5] D. Van Gemert and A. Beeldens, "Evolution in modeling microstructure formation in polymer-cement-concrete", Restoration of Buildings and Monuments 19 (2-3), 97-108 (2013).

[6] R. Bareš, "A conception of a structural theory of composite materials", Brittle Matrix Composites I, eds. A. Brand and I. Marshall, 25-48 (1985).

[7] D. Van Gemert, L. Czarnecki, and R. Bareš, "Basis for selection of PC and PCC for concrete repair", Internation Journal of Cement Composites and Lightweight Concrete 110 (2), 121-123 (1988).

[8] Y. Ohama, "Principle of latex modification and some typical properties of latex modified mortars and concretes", ACI Materials Journal 84 (6), 511-518 (1987).

[9] J. Bijen and Z. Su, "Polymer cement concrete: a contribution to modeling of the microstructure", Proceedings of TC 113: Symposium on properties and test methods for concrete-polymer composites, ed. D. Van Gemert, Oostende, Belgium, 19-27 (1995).

[10] M. Puterman and W. Malorny, "Some doubts and ideas on the microstructure formation of PCC", Proceedings of the $9^{\text {th }}$ ICPIC Congress, Bologna, ed. F. Sandrolini, 165-178 (1998).

[11] H. Schorn and M. Schiekel, "Shape and distribution of polymer particles in PCC, investigated by ESEM", Proceedings of $10^{\text {th }}$ ICPIC, ed. D. Fowler, Hawaii, CD-ROM (2001).

[12] A. Beeldens, D. Van Gemert, H. Schorn, Y. Ohama, and L. Czarnecki, "From microstructure to macrostructure: an integrated model of structure formation in polymer modified concrete", RILEM Materials and Structures 38 (280), 601-607 (2005).

[13] L. Czarnecki and H. Schorn, "Nanomonitoring of polymer cement concrete microstructure", Restoration of Buildings and Monuments 13 (3), 141-152 (2007). 
[14] A. Dimmig-Osburn, "Microstructure of PCC - effects of polymer components and additives,. Proceedings of $12^{\text {th }}$ ICPIC, Chuncheon, Korea, 239-248 (2007).

[15] Y. Tian, Z. Li, H. Ma, and N. Jin, "An investigation on the microstructure formation of polymer modified mortars in the presence of polyacrylate latex", Proceedings of International RILEM Conference on Advances in Construction Materials Through Science and Engineering, eds. C. Leung and K. Wan, Hong Kong, 71-77 (2011).

[16] E. Knapen, A. Beeldens, and D. Van Gemert, "Water-soluble polymeric modifiers for cement mortar and concrete", Proceed-

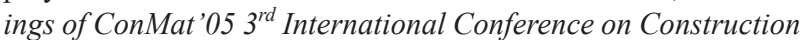
Materials: Performance, Innovation and structural Implications, Vancouver, Canada, (2005).

[17] E. Knapen and D. Van Gemert, "Cement hydration and microstructure formation in the presence of water-soluble polymers", Cement and concrete Research 39 (1), 6-13 (2009).

[18] V. Riley and I. Razi, "Polymers additive for cement composites: a review. Composites 5 (1), 27-33 (1974).

[19] S. Zeng, C. Short and C. Page, "Early-age hydration kinetics of polymer-modified cement", Advances in Cement Research 8 (29), 1-9 (1996).

[20] L. Czarnecki and P. Łukowski, "Influence of polymer admixtures and additives on durability of concrete", Cement Lime Concrete 1, 38-47 (2004), [in Polish and English].

[21] X. Fang, Z. Jing, J. P. Chen, et al., "Study on the interfacial adhesive performance and enhancement mechanism of polymer modified cement paste interface agent", J. Materials Review 26 , 119-122 (2012)

[22] H. Cao, X.L. Zhang, X.H. Guo, et al., „Experimental study on anti-penetration performance of steel fiber reinforced polymer-modified concrete". J.Advanced Materials Research 1030$1032,1100-1103$ (2014).

[23] J. L. Nong, "Study on bonding performance of polymer-modified cement-based bonding composite", Hunan, (2014).

[24] Z. Xu, X. Lu, and L. S. Wang, "The carbonation of concrete and its control measures", J. Ready-mixed Concrete. 3, 43-44 (2014).

[25] X. H. Guo, X. L. Zhang, H. Cao, "Experimental investigation on impact ductility of polymer-modified concrete subjected to falling weight loading", J. Advanced Materials Research 1030 1032, 770-773 (2014).

[26] H. Cao, "Research on freeze-thaw characteristics for polymer modified porous concrete", J. China Building Materials Science \& Technology 5, 25-27 (2013).

[27] Z. H. Wang, "Performance of polymer cement concrete", J. Transportation Standardization 42, 88-90 (2014).

[28] F. Q. Han, X. H. Lin, C. T. Zhang, et al., "Effects of CMC polymer on mechanical properties of cement mortars", J. Building Science 31, 70-74 (2015)

[29] R. Wang and P. M. Wang, "Research development of the properties and mechanism of polymer-modified cementitious materials", J. Materials Review 21, 93-96 (2007).

[30] D. A. Silva, H. R. Roman, and P. J. P. Gleize, "Evidences of chemical interaction between EVA and hydrating portland cement", J. Cement and Concrete Research 32, 1383-1390 (2002).

[31] J. Dikeou, "Review of worldwide developments and use of polymers in concrete", $1^{\text {st }}$ ICPIC'75, London, UK, 2-8 (1975).

[32] J. Geist, S. Amanga, and B. Mellor "Improved portland cement mortars with polyvinyl acetate emulsions", Industrial and Engineering Chemistry 45, 759-767 (1953).
[33] Report on polymer-modified concrete, Report of ACI Committee 548, ACI Publication nr. 548.3R-09, Farmington Hills, USA, 2009.

[34] Y. Ohama, "Polymer-based admixtures", J. Cement and Concrete Composites 20, 189-212 (1998).

[35] A. M. Betioli, J. Hoppe Filho, M. A. Cincotto, et al., "Chemical interaction between EVA and portland cement hydration at early-age", J. Construction and Building Materials 23, 3332-3336 (2009).

[36] D. A. Silva and P. J. M. Monteiro, "Analysis of $\mathrm{C}_{3}$ A hydration using soft x-rays transmission microscopy: effect of EVA copolymer", J. Cement and Concrete Research 35, 2026-2032 (2005).

[37] J. L. MacDonald, U. W. Zwanziger, B. H. Chen, et al., " ${ }^{43} \mathrm{Ca}$ and ${ }^{13} \mathrm{C}$ NMR study of the chemical interaction between poly(ethylene-vinylacetate) and white cement during hydration", J. Solid State Nuclear Magnetic Resonance 40, 78-83 (2011).

[38] H. Ma, Y. Tian, and Z. Li, "Interactions Between Organic and Inorganic Phases in PA-and PU/PA-modified-cement-based Materials", J. Journal of Materials in Civil Engineering 23, 1412-1421 (2011).

[39] Y. Tian, X. Jin, N. Jin, et al., "Research on the microstructure formation of polyacrylate latex modified mortars", J. Construction and Building Materials 47, 1381-1394 (2013).

[40] B. Li, Y. Tian, R. Y. Zhao, et al., "Microstructure and modification mechanism of polyacrylate latex modified mortars", J. Journal of Zhejiang University 48, 1345-1361 (2014).

[41] J. Long, K. Yu, and G. D. Li, "Correlation between cement hydrate and polymers", J. Concrete 3, 35-41 (1995).

[42] J. M. Gao and K. Morino, "Research on polymer modified cement mortar containing silica fume", J. China Concrete and Cement Products 5, 8-10 (2000).

[43] R. Wang, L. J. Yao, and P. M. Wang, "Mechanism analysis and effect of styrene-acrylate copolymer powder on cement hydrates", J. Construction and Building Materials 41, 538-544 (2013).

[44] S. Chandra and L. Berntsson, "Behavior of calcium hydroxide with styrene acrylates polymer dispersion", J. Cement and Concrete Research 11, 125-129 (1981).

[45] J. Plank and M. Gretz, "Study on the interaction between anionic and cationic latex particles and portland cement", J. Colloids and Surfaces Aspects 330, 227-233 (2008).

[46] C. Y. Rha and J. W Seong, "Properties and interactions of cement with polymer in the hardened cement pastes added absorbent polymer", J. Journal of Materials Science 34, 4653-4659 (1999).

[47] S. G. Hu, "Some characteristic analyses in the hydration system of polyacrylamide-monocalcium aluminate", Journal of Wuhan University of Technology 16, 69-73 (1994).

[48] P. Choonkeum, C. Dongwon, and O. Heegap, "Role of ions in the marco-defect-free cementitious materials made with ordinary portland cement", Journal of the Chinese Ceramic Society 24, 382-388 (1996).

[49] D. Gawin, M. Koniorczyk, and F. Pesavento, "Modelling of hydro-thermo-chemo-mechanical phenomena in buildings materials", Bull. Pol. Ac.: Tech 61 (1), 51-64 (2013).

[50] P. Łukowski, "Material modification in concrete", Ass. Of Concrete Producers, Cracow, 2016 [in Polish].

[51] L. Czarnecki and J. J. Sokołowska, "Material model and revealing the truth", Bull. Pol. Ac.: Tech. 63 (1), 7-14 (2015). 